\title{
Analysis of Road Traffic Crashes/Collisions In Ondo State Roads
}

\author{
E.O. Aiyewalehinmi \\ Department Of Civic Engineering The Federal University Of Technology Akure
}

\begin{abstract}
This study highlights the nature of road traffic crashes/collisions occurred on Ondo State roads. A review of previous studies and discussion of vehicle collision/crashes on Ondo State Roads is presented. In the study, crashes/collisions are seen as a major cause of sudden deaths, injuries and permanent disabilities. It examined and analysed records of vehicle crashes/collision data on Ondo state roads from 2005 to 2010. Records showed from 2005 to 2010 a total of 1148 road traffic crashes/collisions, 831 deaths, 3826 suffered different degrees of injuries. Causes identified human error accounts for $41.50 \%$, Road condition $32.17 \%$, while Vehicle and weather $16.83 \%$ and $9.50 \%$. Break down information obtained from the Department of Statistics Ondo State and Federal Secretariat Bureau of Statistics Akure, human error 90\%; mechanical fault 2.4\% environmental $4.7 \%$ and beyond human control $2.9 \%$. The purpose of this study is to highlight the number of deaths and number of injured on Ondo State roads.
\end{abstract}

Keywords: - Road, Vehicle Crashes/Collisions, Sudden death, Injuries, Permanent disabilities

\section{INTRODUCTION}

Vehicle crashes/collisions destroy peoples' lives and properties. They do occur in different categories, take away peoples' lives, damaged properties and cause permanent disabilities. Collisions/crashes can occur between vehicles, vehicle and motorbike, vehicle and pedestrian, motorbike and pedestrian, vehicle and animal, motorbike and animal sometimes vehicle can derail and hit electric pole or a building. They are classified as minor or fatal, depends on the degree of crashes/collisions. Most Nigerians have witnessed serious crashes/collisions where many lives have lost and uncountable properties have destroyed. Quietly and quickly they put them aside and continue with their normal activities. Those that have lost their lives are not remembered except individual families. To many Nigerians reckless driving is not a crime and has nothing to do with road safety.

Aworemi, J.R. (2010) indicated that road vehicle crashes/collisions, only a small percentage is considered unavoidable, unfortunate and misfortune accident, it means that majority of vehicle collision/crashes on Nigeria roads are predictable and can be classified as negligence, ignorance, stupidity, untrained and diabolic type of action. In this study collision/crashes dilemma is classified into four basic groups, human, vehicle, roadway and environment.

Humans are vehicle operators, passengers, and pedestrians, Vehicles are automobiles that move people and goods from one destination to another controlled by humans, Road is a route trafficable by vehicles, cater for pedestrians, bicycles, animals or animal's drawn vehicles constructed by human beings and poorly maintained by human beings and environment is a surrounding defined as a combination of natural and built environment controlled and maintained by human beings. Sometimes Roads crashes/collisions on Ondo State roads are linked with Ondo State weather conditions such as heavy shower, fog, and gale, in such a situation road crashes/collisions is described as unavoidable but can be controlled if precaution is taken seriously. The poor condition of roads in Ondo State works against road safety, State economic activities, peoples' lives and environmental activities. Fatalities, injuries and number of crashes/collisions attract attentions of road safety agents, public and media for a while; within a few minutes it is forgotten, they are not seen as a serious warning to all road users in Ondo State. Records of number of deaths, injured and damaged vehicles are available but records of other valuable damaged goods are not available in Ondo State. Ondo State residents are easy to acknowledge things and it is also easy for them to forget immediately. Road accident in Ondo State does not attract media attention or State law makers. The

statistical records show that in Ondo State $92 \%$ of road crashes/collisions are caused by the road users. Reasons for vehicle crashes/collisions accidents on Ondo State Roads indicate that transport operators ignored traffic rules and regulations and continue with their attitudinal behaviour such as driving carelessly, driving under the influence of Alcohol and also engaged in bitter augments with their passengers. In the analysis of the data obtained road safety found that human error was $90 \%$; mechanical fault was $2.4 \%$ environmental $4.7 \%$ and beyond human control was just $2.9 \%$. 


\subsection{CAUSES OF ROAD CRASHES/COLLISIONS}

The cause of crashes/collisions can be vary, depends on situation, for example a pedestrian crossing the road without taken into consideration traffic condition he/she may be hit by a vehicle or motorbike or school children crossing the without proper traffic control may be victims. If a vehicle driver is distracted and failed to identify an object in front of him or her may as well hit the object or crash into somewhere else. However, information obtained from the Department of Statistics Ondo State and Secretariat Bureau of Statistics Federal Secretariat Akure categories the causes of crashes/collision on Ondo State roads into the following: Distraction while driving; over speeding; intoxicated driving; careless driving; weather; underage and unexpected tyre expansion.

\subsubsection{Distracted Driving}

According to statistical reports distraction top the lists of crashes/collisions in Ondo State. The reasons for distraction are attributed to receive and make telephone calls, including text messages, arguments and discussions with passengers on the wheel.

\subsubsection{Excessive Speeding}

Excessive speeding is prone to crashes/collisions; this has always been recognized as major factor road crashes/collisions in Ondo State. Over speeding is rated second on the list causing death/disabilities in Ondo State. For-example in Australia excessive speeding contributes up to $30 \%$ of fatal crashes in that country. All over the world excessive speed is considered dangerous and disposed to crashes/collisions.

\subsubsection{Drunk Driving}

Drugged driving is third on the lists. Driving under the influence of alcohol or drugs is susceptible to crashes/collisions and is rated third causing death/disabilities in Ondo state. A driver under the influence of drug is unable to focus or concentrate properly all passengers in the vehicle are in danger.

\subsubsection{Reckless Driving}

Irresponsible driving is common among young people and is rated fourth in causing death/disabilities on Ondo State Roads. Irresponsible drivers are very aggressive, impatient and always in haste.

\subsubsection{Rain}

Weather is beyond human control and is listed fifth. Crashes/collisions do occur during the rainy season especially when potholes are covered by flood and not visible, especially where the moving vehicle has no heater or air-condition to clean the screen, driving in this condition in Ondo State is dangerous.

\subsection{Teenage Drivers}

Under aged driving is rated sixth in causing accidents on Ondo State roads. Under aged drivers are impatient, reckless, inexperience and they do not obey traffic rules and regulation.

\subsection{7: Tyre Blowouts}

Sudden flat tyre or expandable tyre is rated seventh the least on the lists. According to the report Expandable tyres do cause serious crashes/collisions on Ondo State roads.

\section{URBAN COMMOTION}

In looking at situations in Akure today as the Capital of Ondo state compared to other cities in Nigeria, Vehicle operators are facing multiple problems when driving in congested and overcrowded Akure city, specifically by having the senses overloaded by the vast amount of information that needs to be continuously processed - this type of condition is described as information overload. Overload is a typical information city drivers bump into are traffic sign, traffic signals, information about detour, billboard and other advertisements, sirens, loud music from passing vehicles, vehicle changing lanes, pedestrians and much more.

\subsection{Situational Judgment}

Vehicle operators' experience, knowledge; education and attitudes are very important in judging vehicle drivers' capabilities. Operator's life-style contributes to poor judgment for example carelessness, using cigarettes, medication, alcohol and drugs to keep awake. Careless to pay proper attention to road situation and traffic environment activities, speeding and disregarding traffic rules and regulations or traffic control devices, confusion or unfamiliarity contribute to road crashes/collisions in Ondo State. This indicates that human 
behaviour /attitude and human thinking are complex and difficult to isolate, as they are transient in nature. Human capabilities, knowledge, judgement, attitude, alertness, health, driving skill, age, custom, habits, strengths and emotional factors contribute to human error and they are difficult to separate and identify.

\subsection{1: Maintenance}

According statistical report only small percentage of crashes/collisions is attributed to mechanical failures such as expansion (tyre eruption), brake failure, steering wheel problems or other related factors.

The road conditions, (pavements, shoulders, traffic control devices and intersections) are poorly maintained in Ondo State. In Ondo State roads, there are few traffic control devices, complex intersection with excessive signage posting, poorly positioned and other related problems. Engineering principle and ethics all highways must be designed to serve the needs of all road operators, users and the safety of the community. Engineering principle and ethics is missing in Ondo State.

\subsubsection{Weather}

The climatic and environmental condition is a factor that contributes to vehicle crashes/collisions on Ondo state roads. Weather contributes to wetting pavement that reduces friction between the asphalt road surfaces and moving vehicles. A few percentage of severe crashes/collisions occurred on Ondo State roads through weather. For-example smoke, fog sunrise and sunset can reduce visibility of the driver of a vehicle. Wind gust can affect vehicle stability, especially of large trucks and light weight vehicles such as bicycles and motorcycles.

\section{ROAD TRAFFIC SAFETY}

The term road safety cut across all aspects of road users and community daily activities.

The purpose of road safety is to preclude or circumventing crashes/collisions that can cause harm, death, injuries, and property damage. The term road safety can be expressed as normative safety, Substantive safety and Perceived safety.

3.1: Normative safety: Normative safety is a term used to describe products or designs that meet application design standards and protection.

3.2: Substantive safety: Substantive or objective safety means that the real -world safety history is favourable, whether or not standards are met.

\section{3: Perceived safety:}

Perceived of subjective safety refers to the level of comfort of road user. For example, traffic signals are perceived as safe, yet under some circumstances, they can increase traffic crashes at an intersection. Traffic roundabout have a generally favorable safety record, yet often make drivers nervous. The World Health Organization (2004) reported that more than 1.2 million people were killed and about 50million persons injured on the road around the world each year, among them are children 10-19 years of age. The report emphasized the situations of road safety in developing world.

\section{THE COST OF ROAD TRAFFIC CRASHES/COLLISIONS IN NIGERIA}

The cost of crashes/collisions can be seen in two different dimensions (tangible cost and intangible cost). Tangible costs include cost of property damage, administrative cost and medical expenses involved in the crashes/collisions. Intangible costs include losing output and pain grief, suffering or permanent suffering due to crashes/collisions. Unfortunately the information relating to this problem is not available in Ondo State as at the time the data was collected.

\section{1: Tangible costs}

In economic term tangible costs can be related to the costs of property damaged such as repairing and replacement of vehicle parts, including lost in revenue during the period of damaged vehicles are out of service. This type of information can only be assessed or obtained from the insurances companies. Unfortunately this type of information is not available in Ondo state at the time of this study. Regrettably, most of these vehicles are not insured in Ondo State.

\subsection{2: Intangible costs}

Intangible costs can be associated with national economy productive capacity due to time delays of victim's business such as time for recovery and rehabilitation of the victim's vehicles sent to the workshop, time 
for medical treatment in hospital and even non -hospital bill. This information also is not available in Ondo State.

\section{BACK GROUND OF THE STUDY AREA}

Ondo State was created in 1976. It is bounded by Kwara and Kogi State in the North, Edo State to the East, Delta State to the South East, Osun, Ogun, and Ekiti States to the west and the Bright of Benine of the Atlantic Ocean to the south. The land mass of Ondo state is 14, 606 square kilometres with a population of 3 , 414,024 (NPC, 2006)

\section{1 : Research Approach}

The research approach is designed specifically to determine how to improve the quality of drivers driving on Ondo state roads and reduce the rate of crashes/collision number of persons killed deaths and number of persons injured. The study uses secondary data which was obtained from the Department of Statistics Ondo State and Secretariat Bureau of Statistics Federal Secretariat Akure. The purpose of collecting data from Research and Statistic Department, Ministry of Economics, Planning and Budgeting, Ondo State Secretariat, Akure and Bureau of Statistic, Federal Government Secretariat, AKure, was to analyse the crashes/collisions from the year 2005 to 2010 . The advantage of the data was that the precision of the data has not lost, the quality and quantity of the data are quite elaborates and explanatory.

Figure 1a below shows the road Traffic Accident data from January to December 2005 in Ondo State. The Figure classifies road traffic crashes/collisions into serious, Fatal and Minor. The Figure1 also shows the total number of persons killed and total number of persons injured every month from January to December 2005. As can be seen from the figure the highest death recorded was in the month of May while June, Aug and December recorded Zero death. The total number of deaths was 64 while the total number of injured was 174.The highest number of persons killed in the year 2005 was recorded in May (21) while lowest was recorded in the month of June, August and December zero deaths. Figure 1a below shows the highest number and months of persons injured February (39) and August (4) 2005.

\section{ANALYSIS OF DATA}

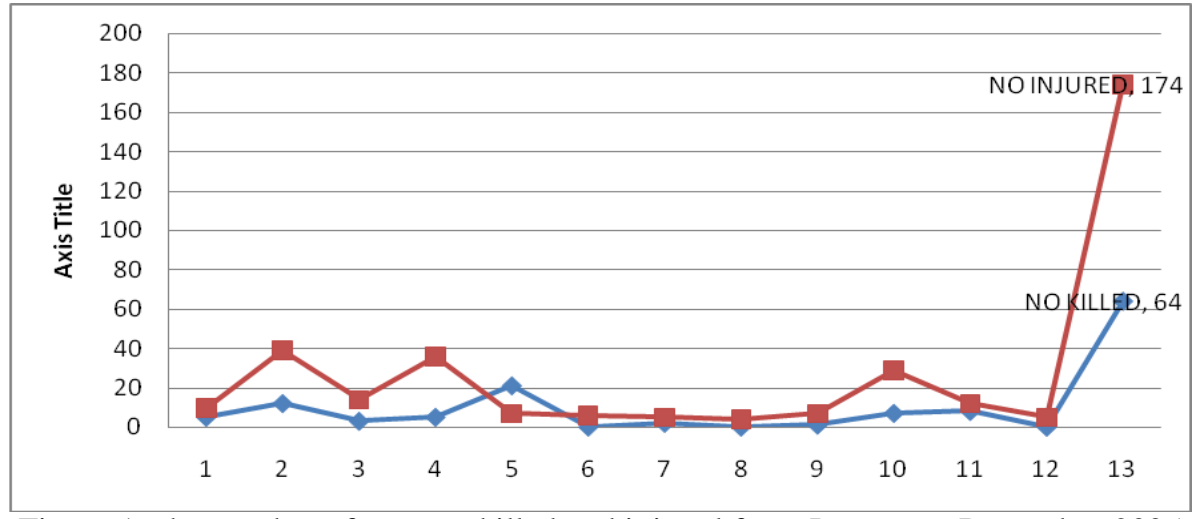

Figure 1a the number of persons killed and injured from January to December 2005

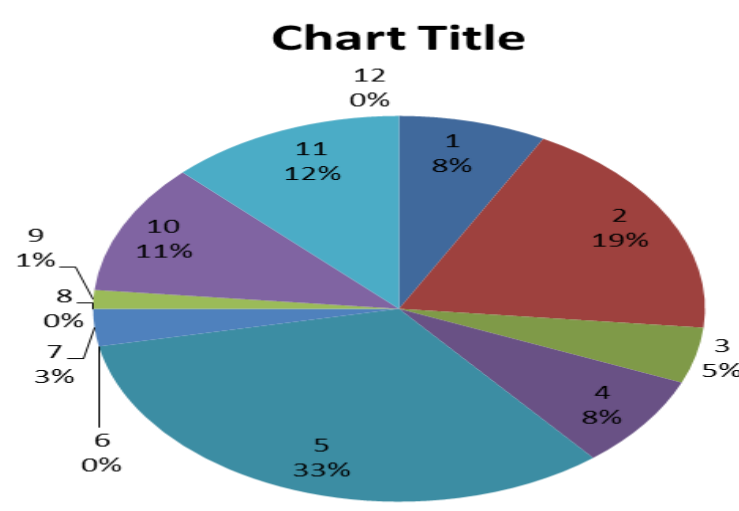

Fig. 1 Figure 1b: Percentage of persons killed from January to December 2005 
Figure 1b shows the percentage of number of persons killed from January to December in the year 2005. In the month of May 33\% of deaths were recorded the highest in year 2005 while, June, August, and December recorded zero per cent death rate.

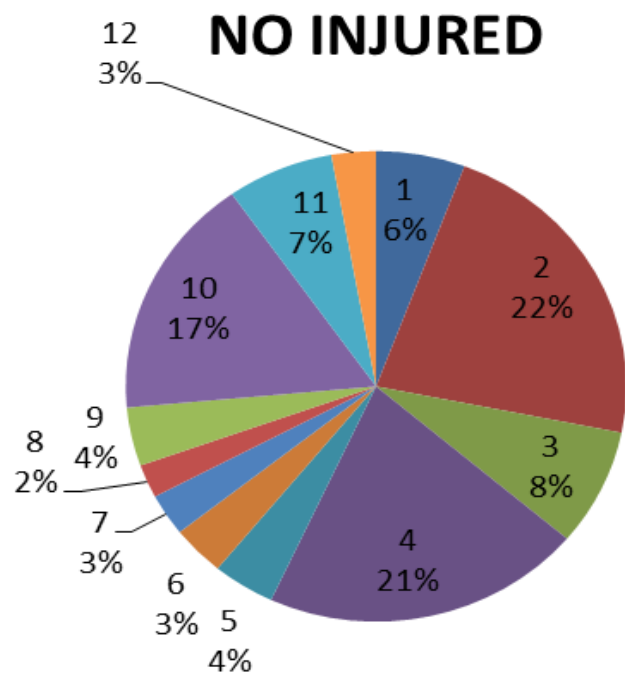

Fig 1c. Percentage of number persons injured from Jan to Dec. year 2005

Fig. 1c shows the percentage of injured persons from the month of January to the month of December in the year 2005.The highest Percentage of persons injured was 22\% recorded in February while the lowest was recorded (2\%) in the month of August 2005.

Figure2.0below shows the Road Traffic crashes/collision data from the month of January to the month of December 2006 in Ondo State. The total number of persons killed and total number of persons injured from the month of January to the month of December 2006 are shown in the figure. The highest number of persons killed was (26 persons), recorded in the month of December while the month of November was Zero. The highest number of persons injured was recorded in the month of August (37) followed by the month of June (28 persons) and the month of January (26 persons). Regardless of the number of injured the month of February and August and November recorded no deaths in the year 2006

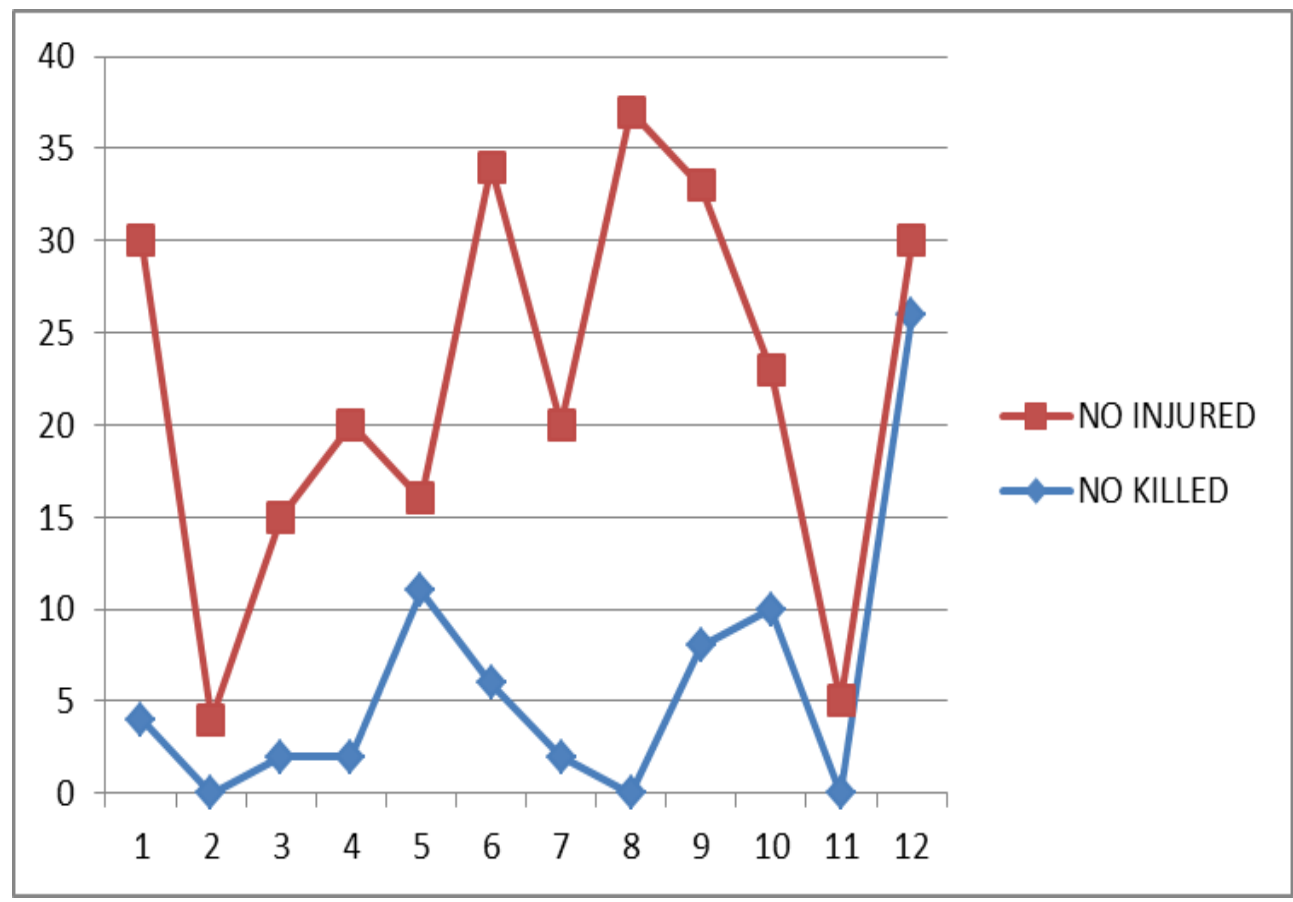

Fig.2a the number of deaths and injured from January to December 2006 


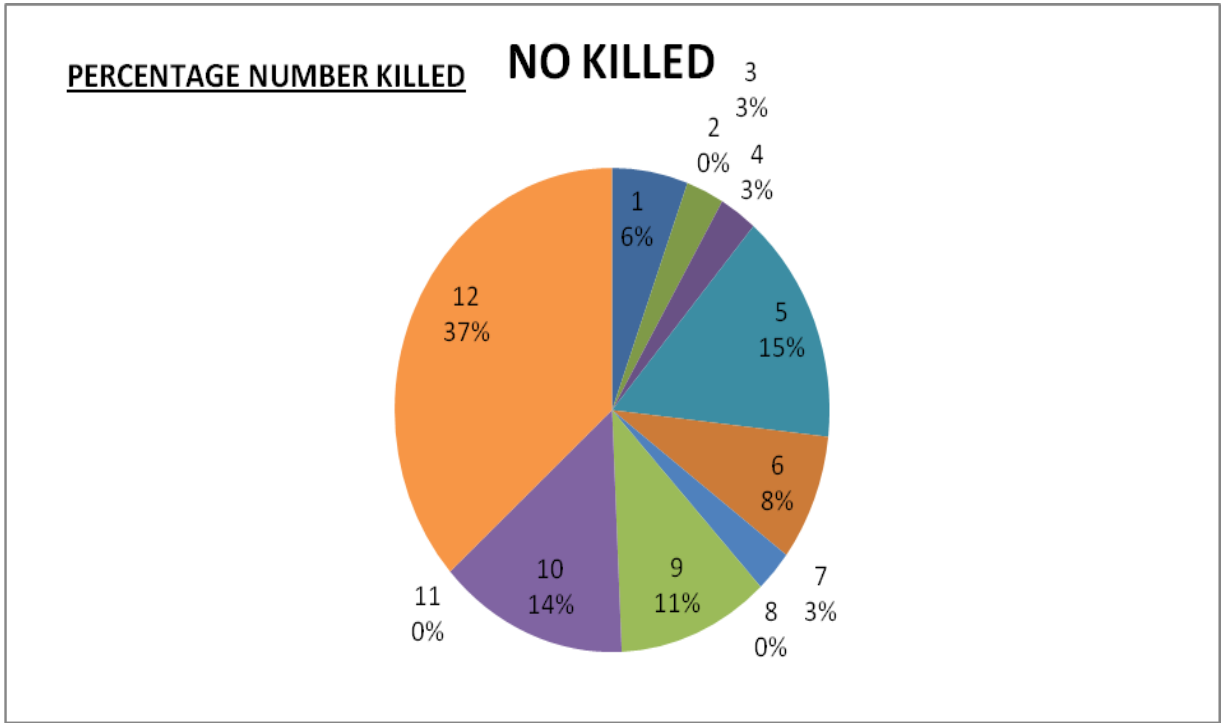

FIG 2b Percentage of number persons killed from January to December 2006

Figure $2 b$ above shows the highest percentage of number of persons killed from the month of January to the month of December the year 2006. The highest Percentage number of persons killed was recorded in the month of December (37\%) while February, August and November recorded zero percentage death rates.

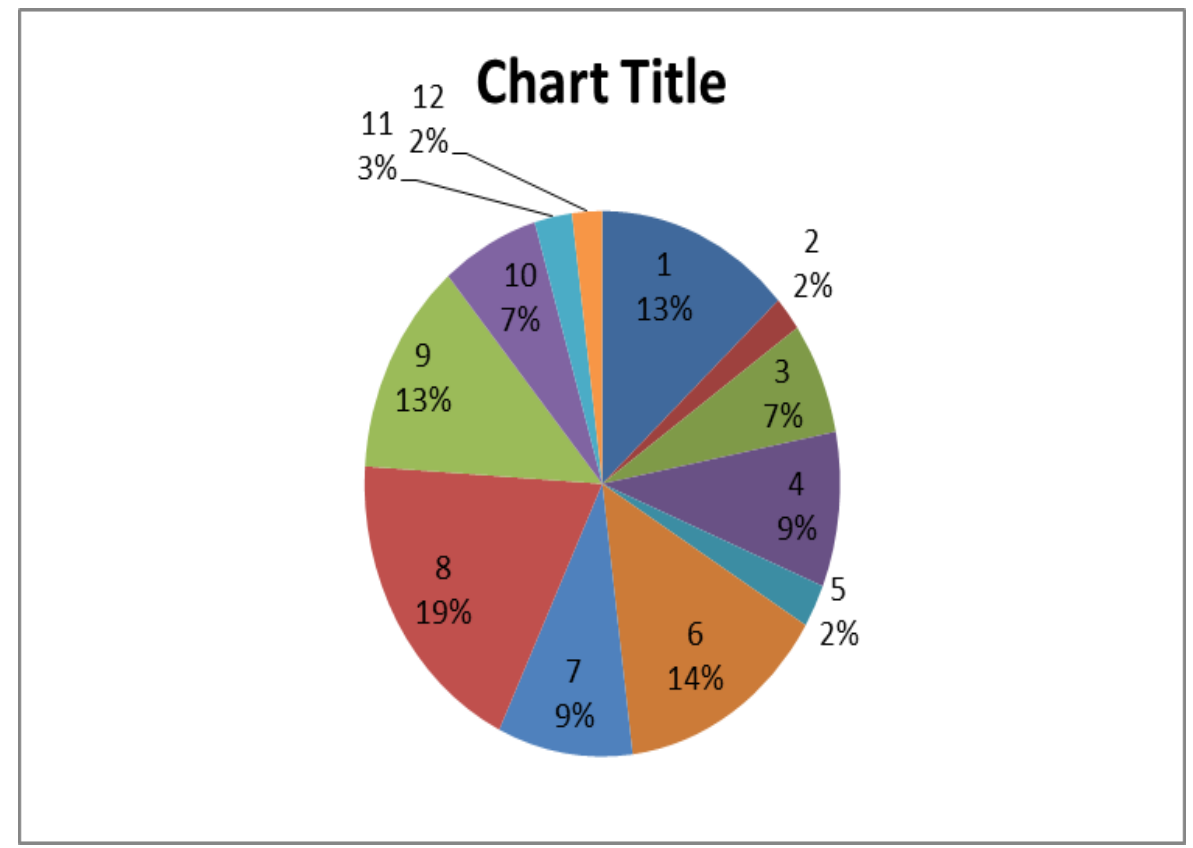

Fig 2c Figure 2c percentage of number injured persons from January to December year 2006

FiguFigure $2 c$ above shows the percentage of number injured per month in the year 2006. The highest percentage Per number of persons injured was (19\%) in August while the lowest was recorded in the month of February and May (2\%).

Figure3a below communicates the total number of Road Traffic crashes/collision data from January to December 2007 on Ondo State roads. The Figure 3a shows the number of persons killed and number of people injured from the month of January to the month of December 2007. As can be seen in the figure the highest number of deaths (26) was recorded in the month of July while the month of January (4) was the lowest recorded 2007. Also the highest number of persons injured was recorded in the month of March (146) while lowest was recorded in the month of February (38) in the year 2007. 


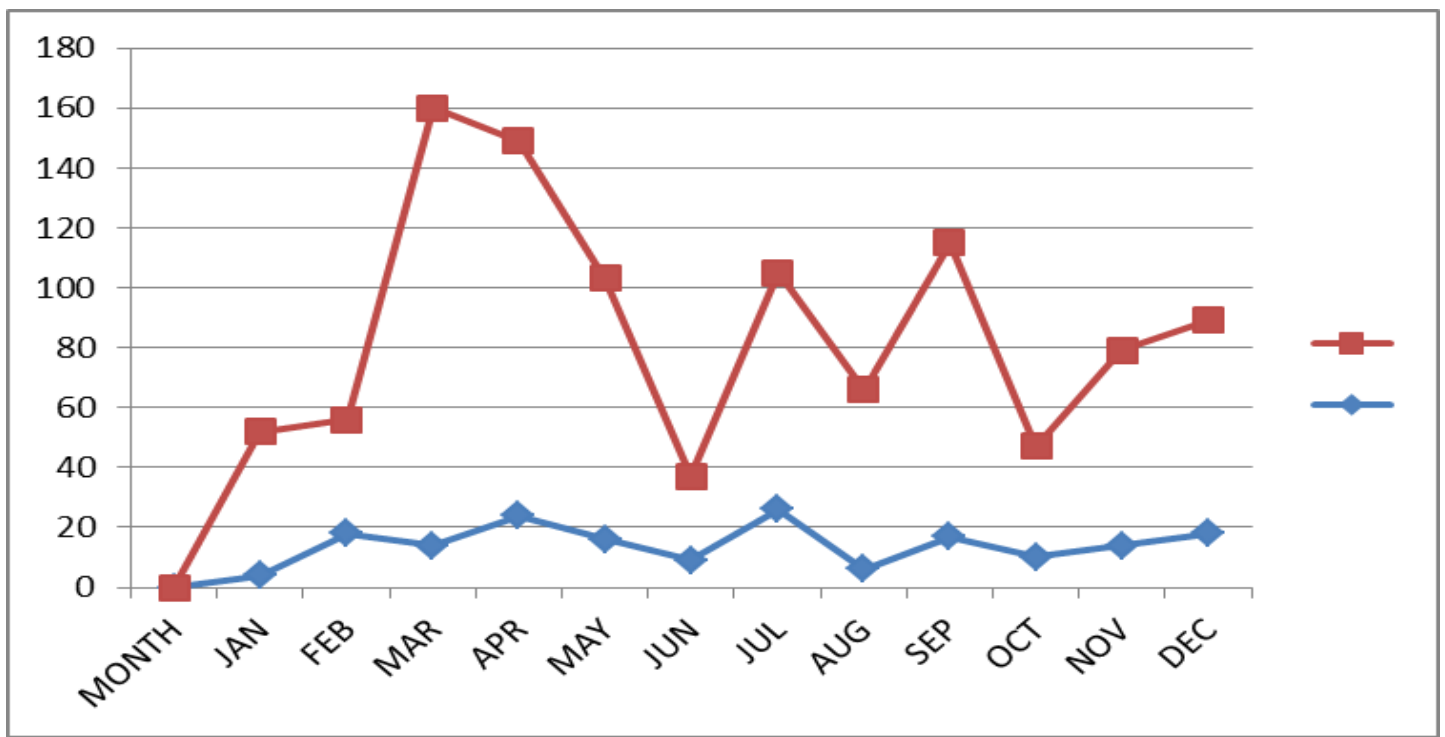

Fig 3a Number of persons killed and injured from January to December year 2007

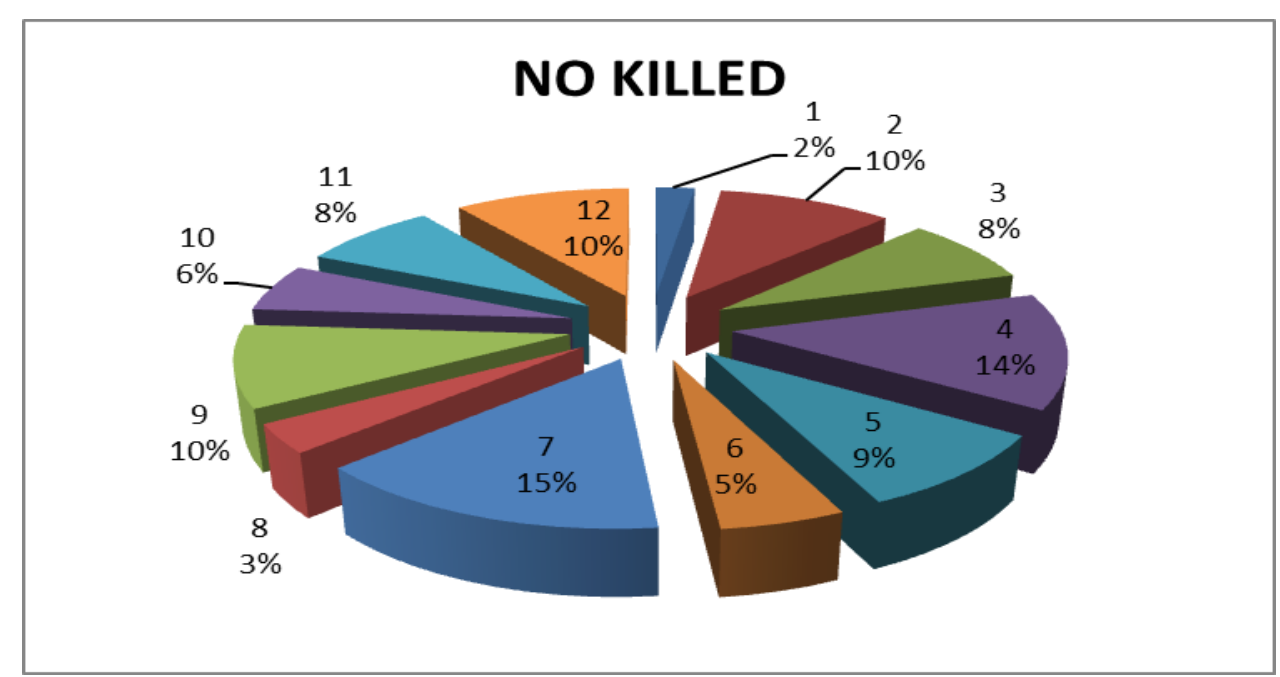

FIG 3b: Percentage of persons killed and injured from January to December 2007

Figure $3 \mathrm{~b}$ shows the percentage of number of persons killed from the month January to the month of December in the year 2007. The highest percentage of number of persons killed (15\%) was recorded in the month of July while the lowest (2\%) was recorded in the month of January 2007.

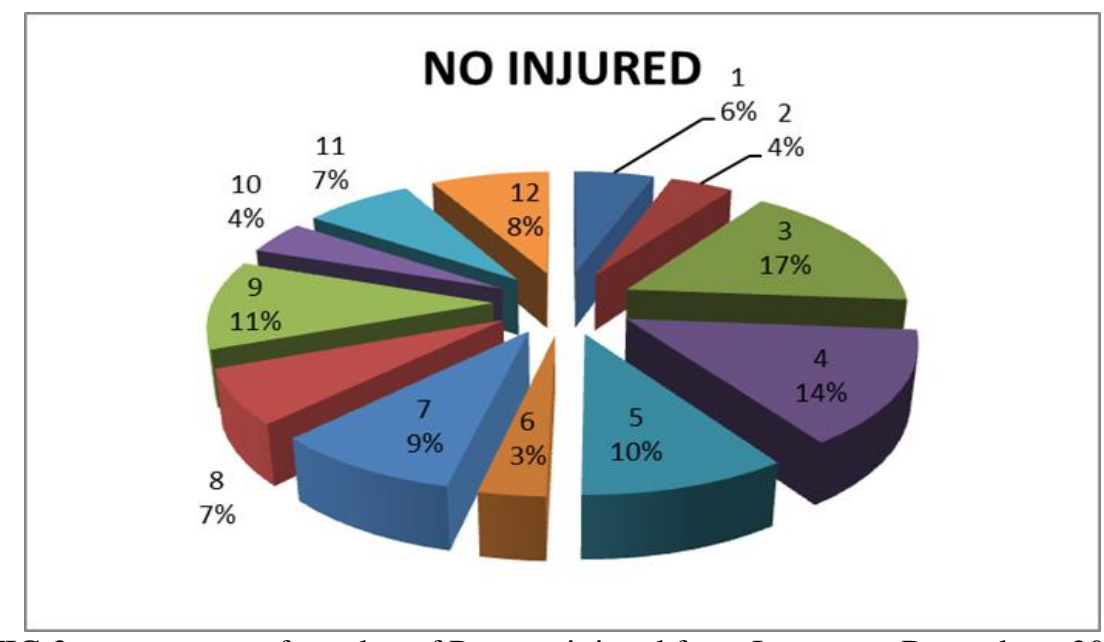

FIG 3c percentage of number of Persons injured from January to December 2007 
Figure $3 \mathrm{c}$ shows the percentage of number of persons injured from the month of January to the month of December 2007. The highest Percentage of persons injured (17\%) was recorded in the month of March 2007 while the lowest 3\% was recorded in June 2007.

Figure $4 \mathrm{a}$ shows the number of persons killed and number of persons injured from the month of January to the month of December 2008. As can be seen in the figure 4a the highest death rate was recorded in the month of April (20) while the lowest was recorded in the month of September (1) 2008. The Figure 4b below shows the percentages of persons killed from the month of January to the month of December 2008. According to the Figure $4 \mathrm{~b}$ the highest percentage of death $15 \%$ was documented in April while the lowest was recorded in September 1\% in the year 2008.

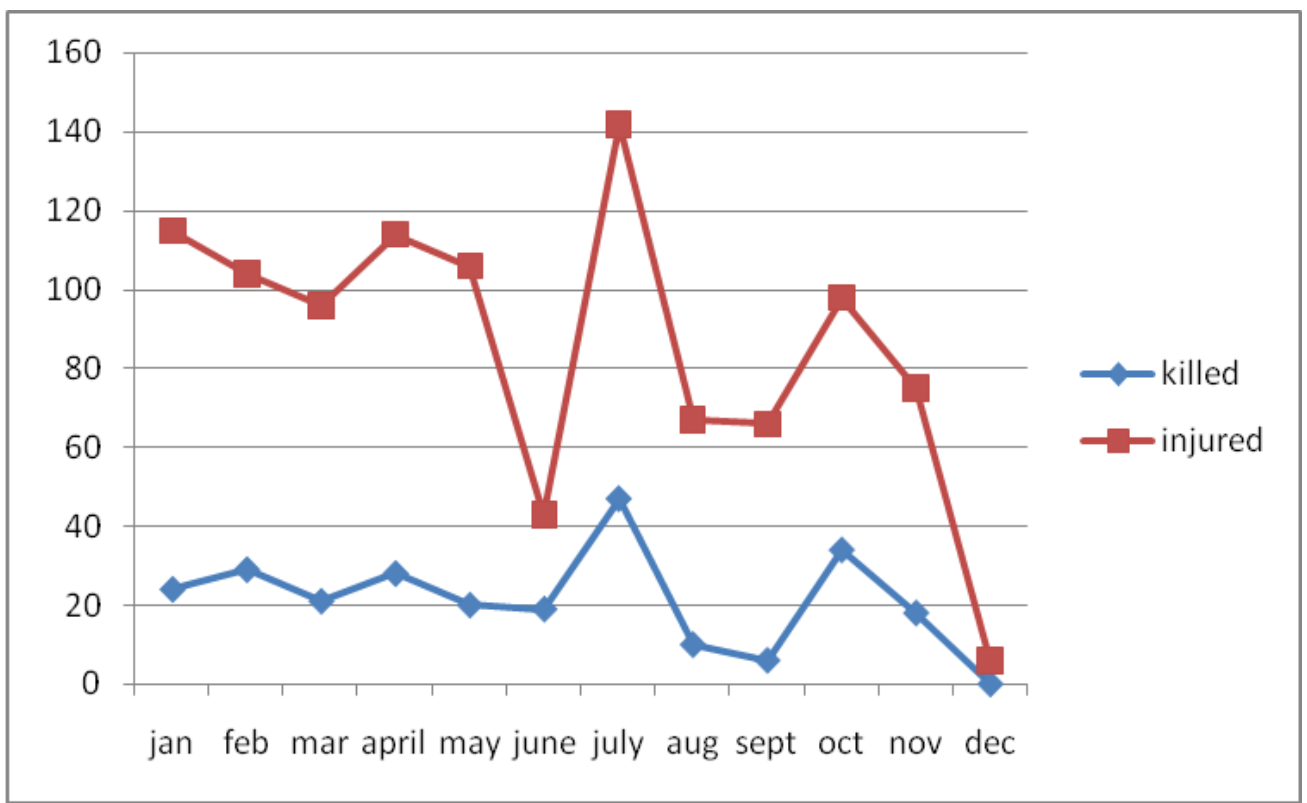

Fig. 4a the number killed and injured year 2008

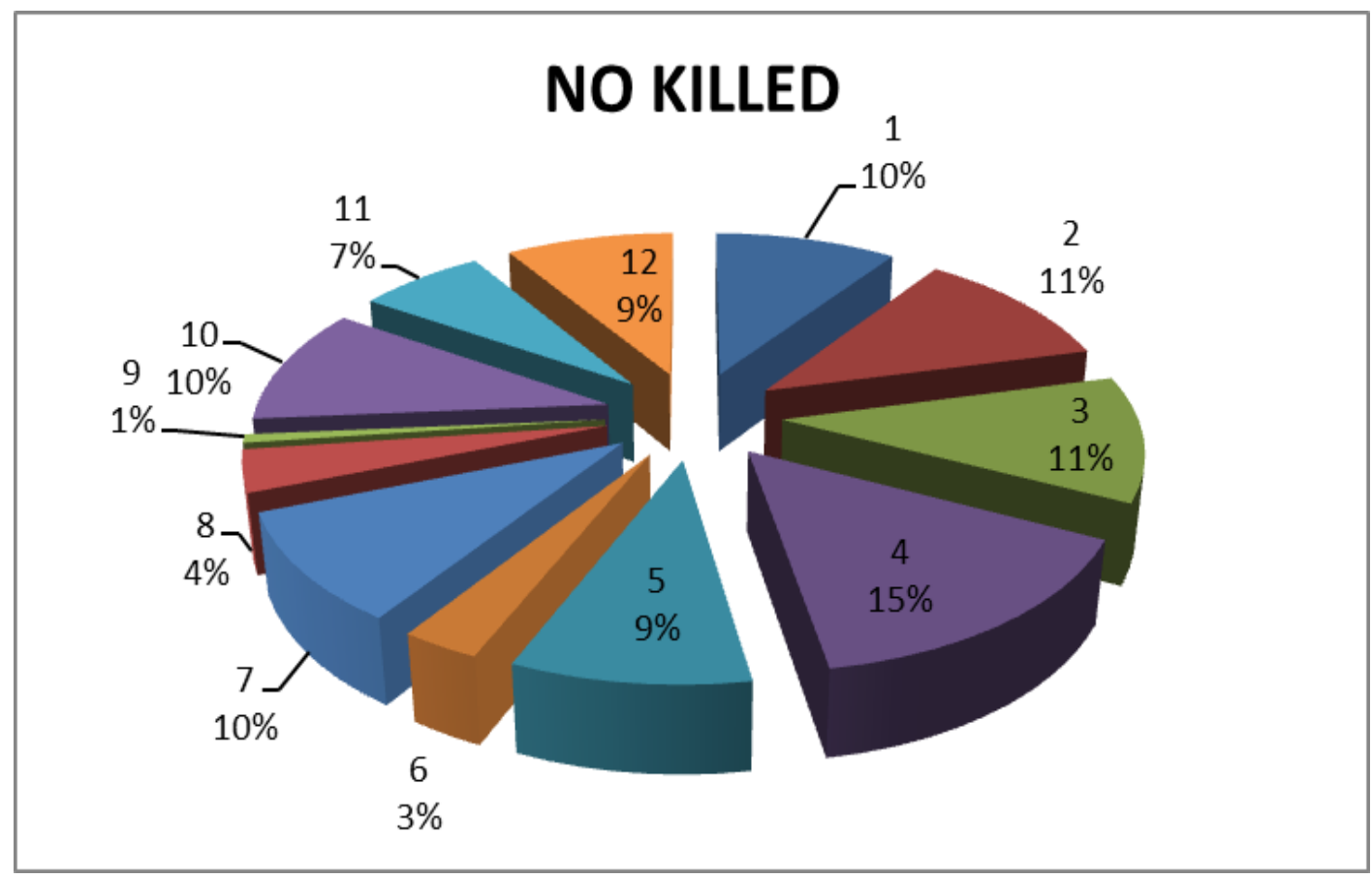

FIG $4 \mathrm{~b}$ percentage of number persons killed from January to December 2008 


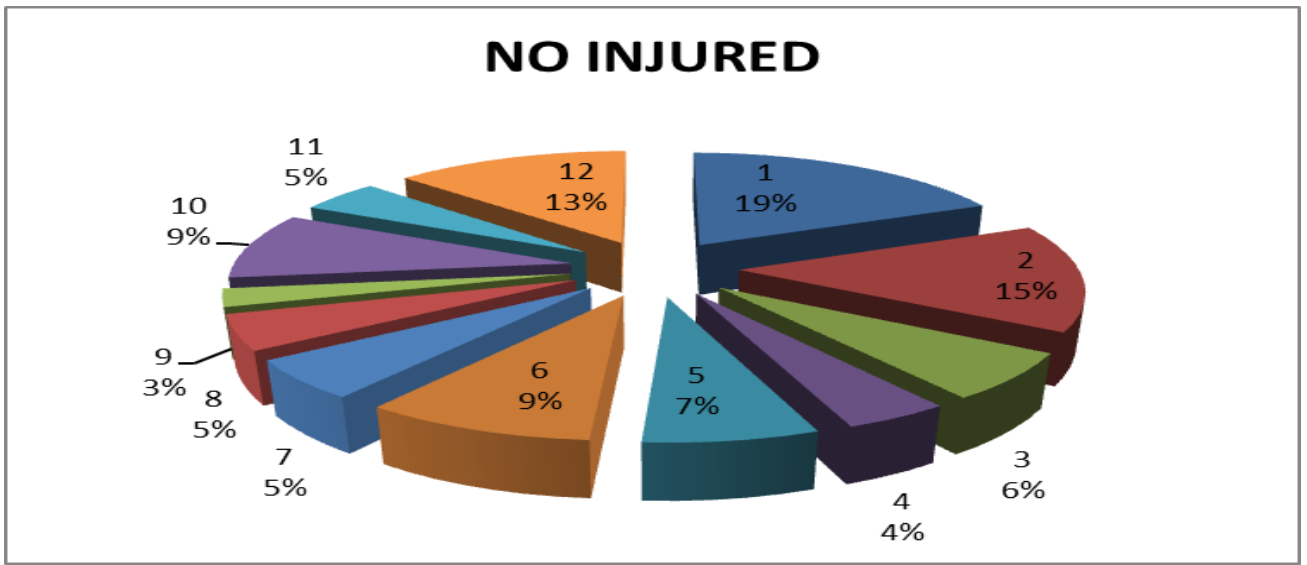

FIG 4c percentage of number from January to December 2008

As can be seen from the Figure $4 c$ above the highest percentage of persons injured was documented In the month of January (19\%) while the lowest (3\%) was recorded in the month of September.

Figure 5a sFigure 5a shows the number of persons killed and number of persons injured from the month January to the month of the month of eDcember 2009. As can be seen in the figure the highest number of persons killed was 32 recorded in theNovember month of November while the lowest zero was recorded for the month of May in year 2009. At the same time the total highest of the total number of persons injured was 92 recorded in the same month and total causalities were 124.

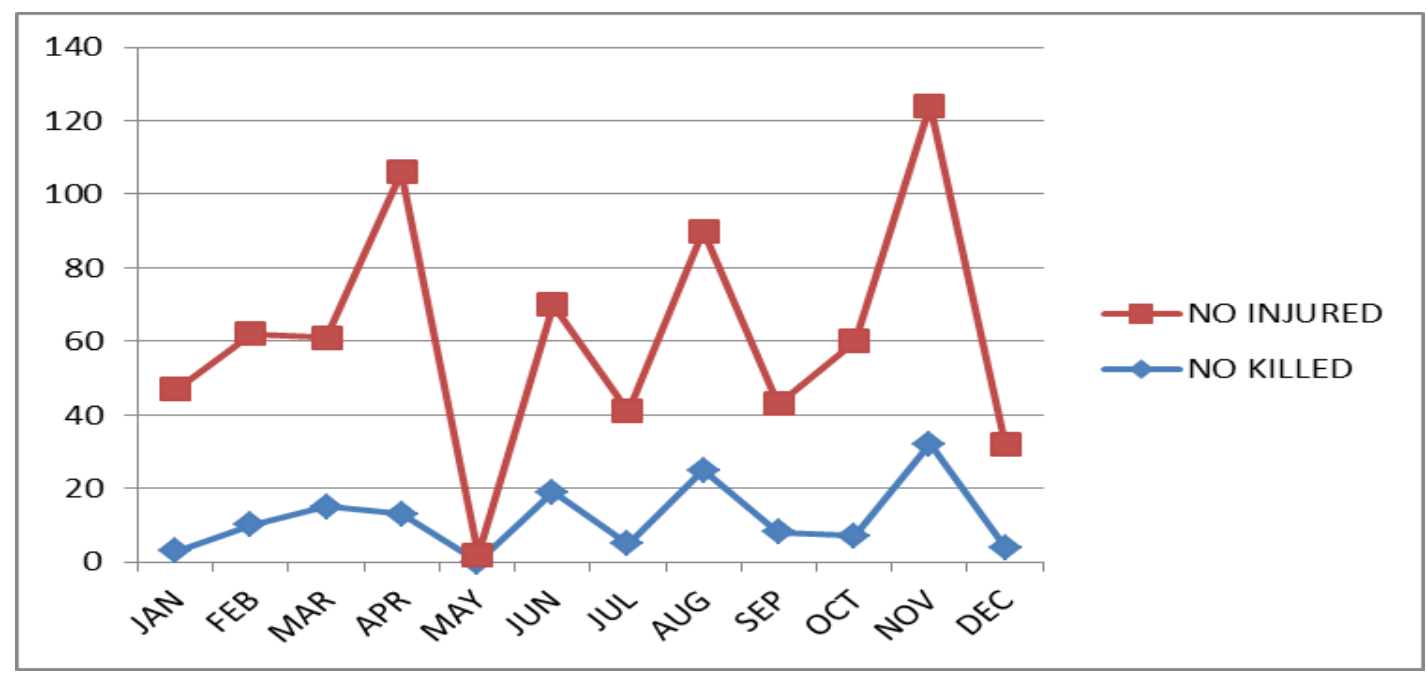

FIG 5a The number killed and injured in the year 2009

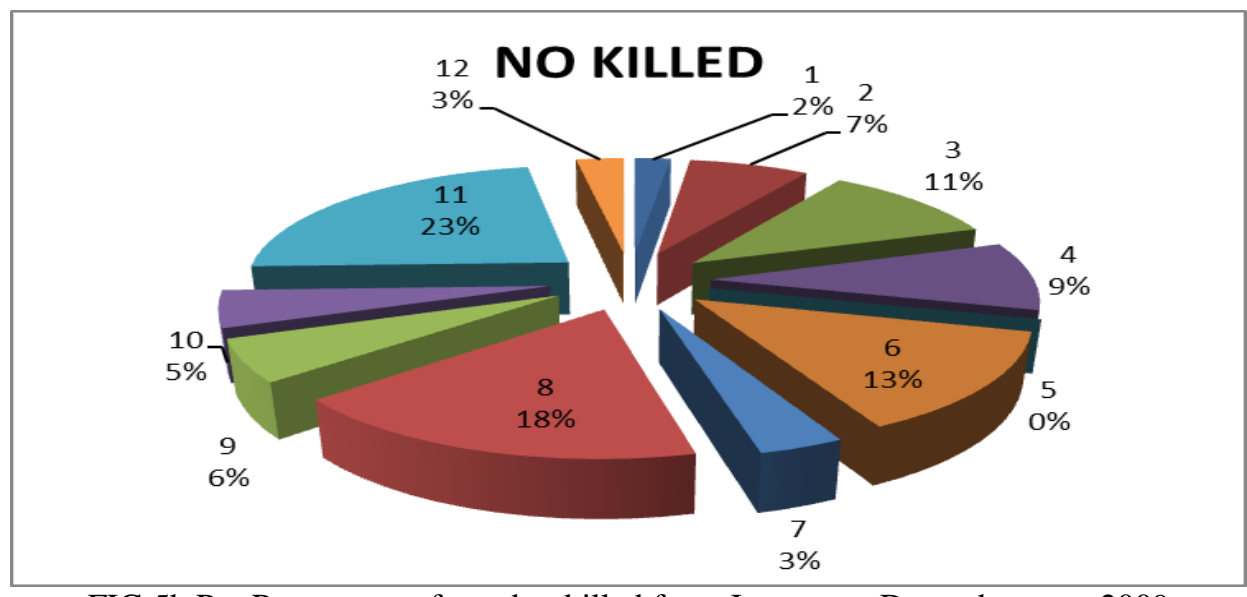

FIG 5b Per Percentage of number killed from January to December year 2009 
Figure $5 \mathrm{~b}$ shows the percentage of number of persons killed per month in the year 2009.

The highest Percentage number of persons killed was 23\% recorded in August while the lowest $0 \%$ was recordedWrecor in May 2009.

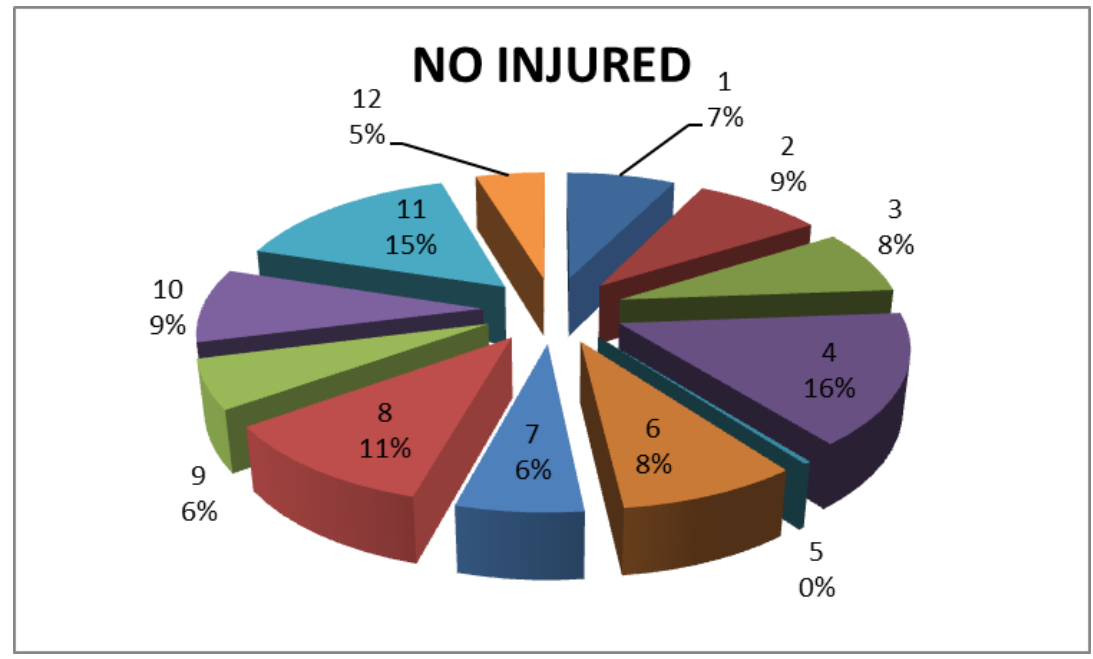

FIG 5cThe percentage of number injured per Month in the Year 2009

Figure 5c shows the percentage of number injured per month in the year 2009.

The highest Percentage number injured 16\% was documented in April while lowest percentage was recordedin the month of May $0 \% 2009$.

Figure 6a below shows the number of persons killed and number of persons injured from the month of January to the month of December 2010. As can be seen from the Figure 6a below the highest number of persons killed in the crashes/collisions was recorded in month of July to be 47 (Male 42,Female 1 and children 4). While the lowest recorded in the month of December (zero). Figure 6a theHighest number of persons injured 142 (male 117, Female 1 and children 24) was recorded in the month of July and the lowest $6(\mathrm{M}=6 \mathrm{~F}$ $=0 \mathrm{C}=0$ ) was recorded in the month of December 2010 .

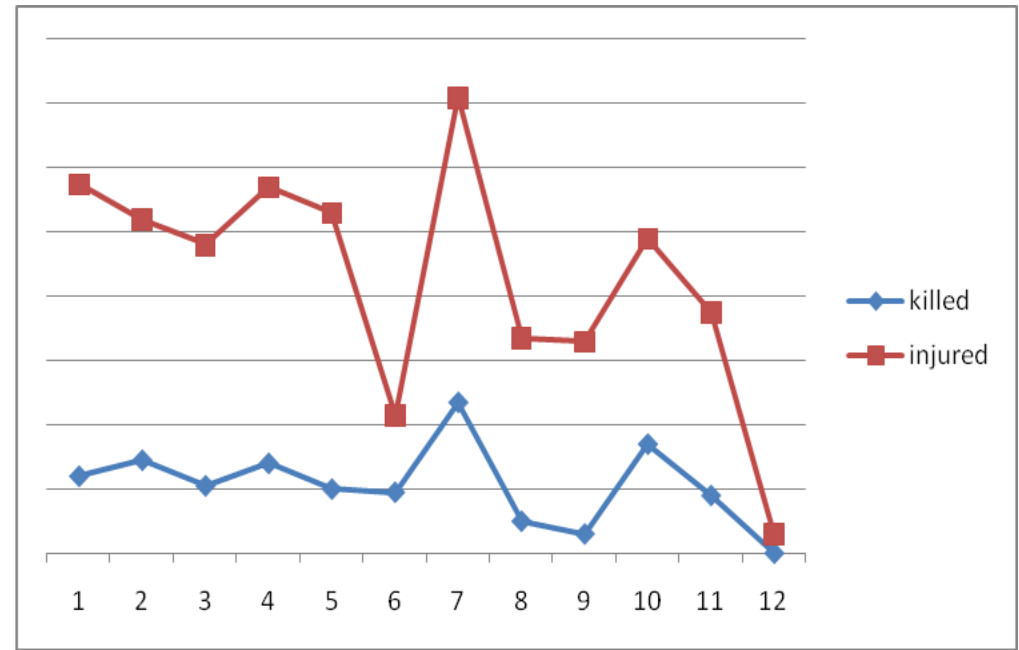

Fig 6a number killed and injured per month in a year 2010.

was

Figure6b shows the percentage of number of persons killed per month in the year 2010.

The highest Percentage number of persons killed was $18 \%$ recorded in July while the lowest $0 \%$ was recorded in December 2010. 


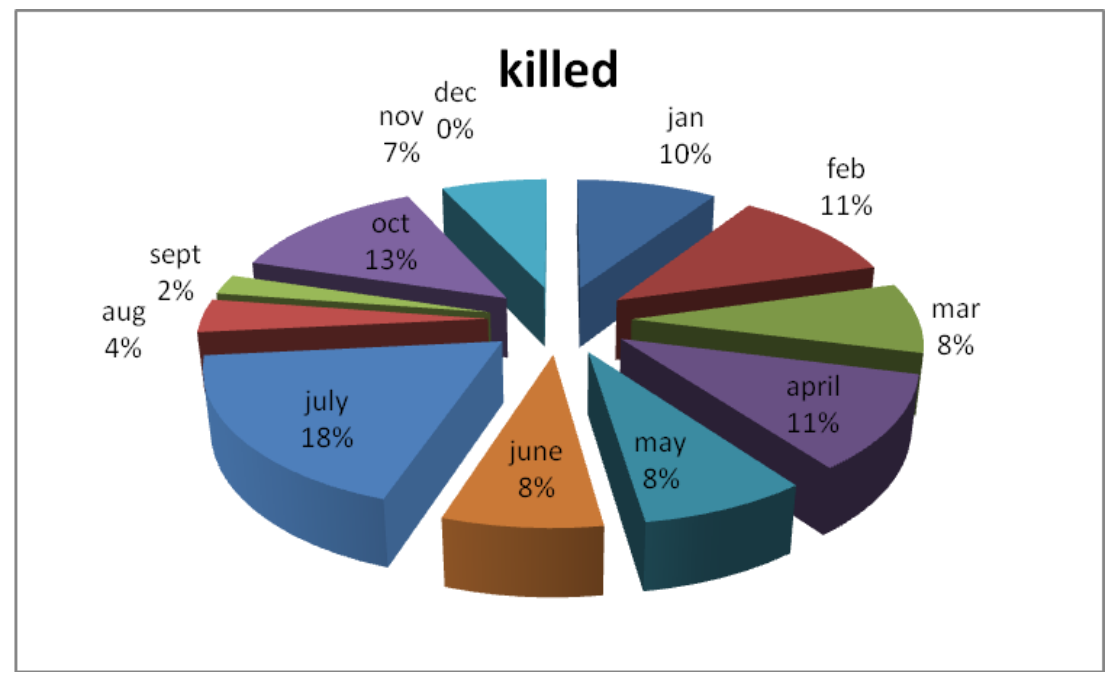

Fig 6b percentage of number killed 2010.

Figure 6c shows the percentage of number people injured every month in the year 2010. The highest Percentage number injured $14 \%$ was documented in July while lowest percentage was recorded In the month of December $1 \% 2010$

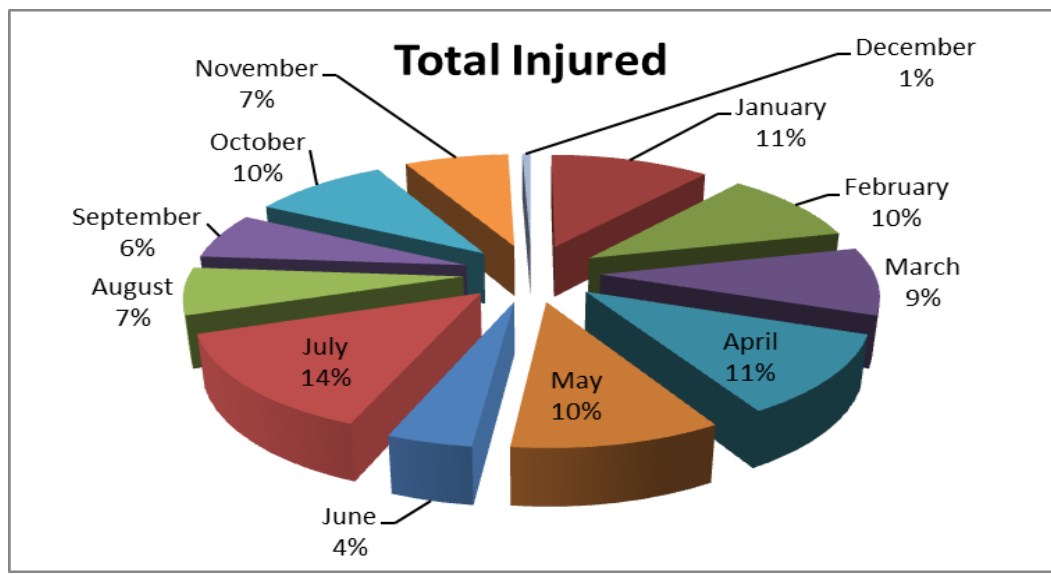

Fig 6c.percentage of number of person injured 2010.

Figur KEY - $\mathrm{M}=$ Male, $\mathrm{F}=$ Female, $\mathrm{A}=$ Adult, $\mathrm{C}$ children

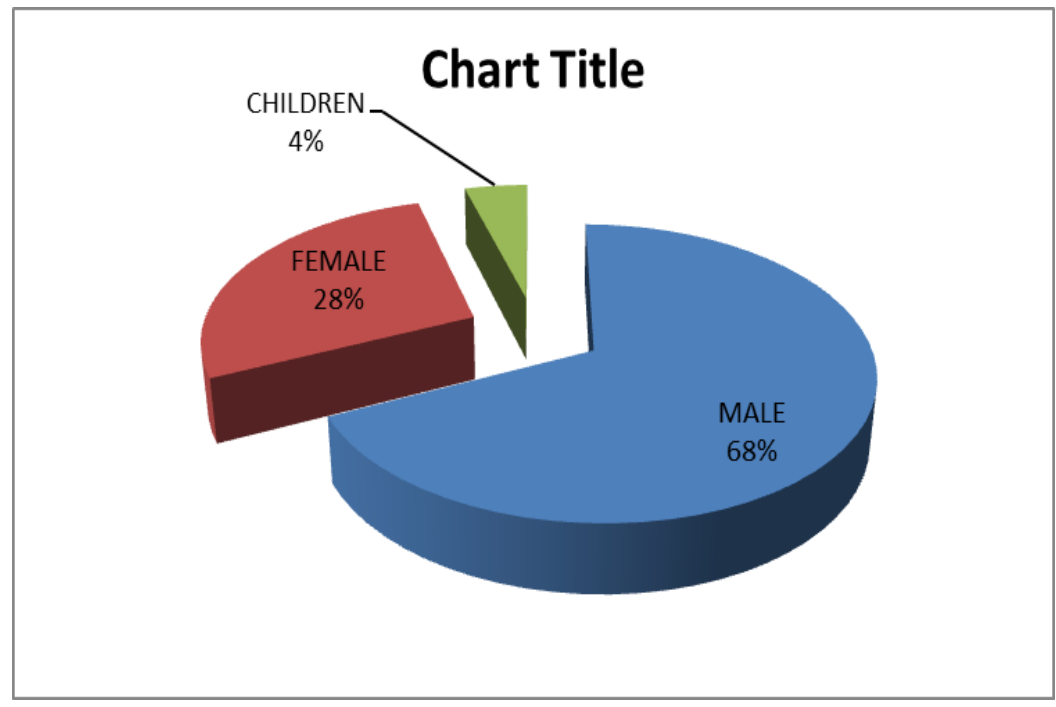

Fig 6d show the percentage category injured in the year 2010. 
Figure $6 a$ above shows the percentage of Male, Female and children injured on road accidents from The month of January to the month of December 2010. It shows that $68 \%$ of male, $28 \%$ of female and $4 \%$ of Children injured on Road crashes/collision in the 2010.

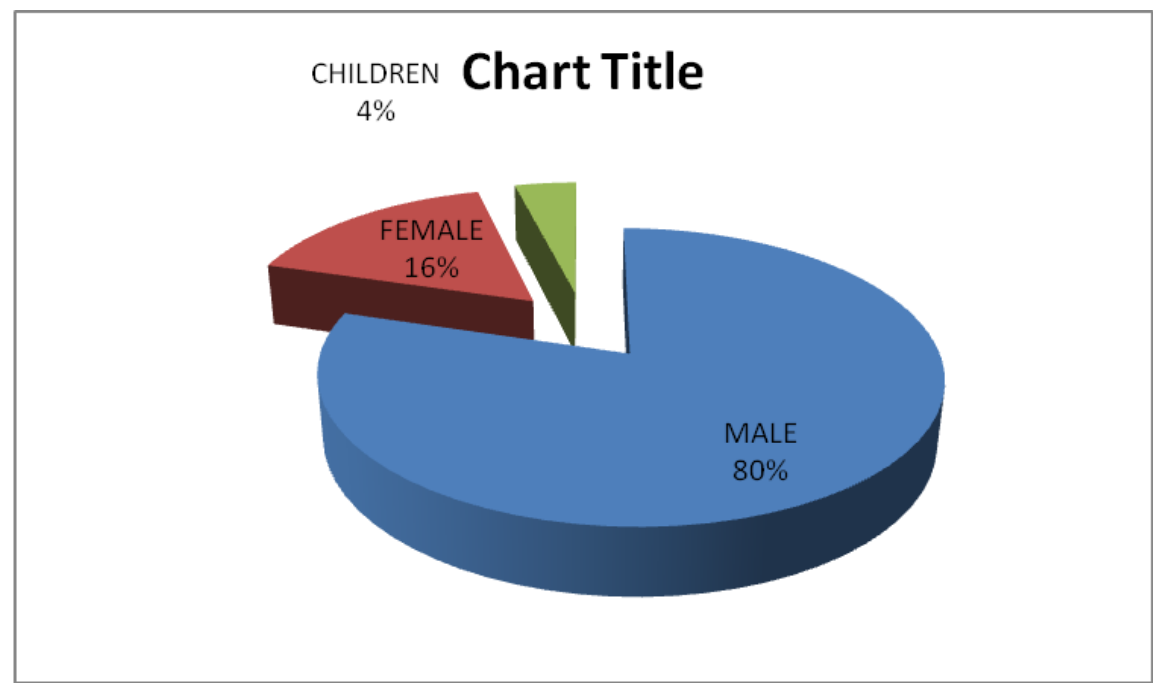

Fig 6e Percentage category killed in year 2010.

Figure 6e shows the percentage of Male, Female and children killed on road accidents from the month of January to the month of December 2010 on Ondo State roads. It shows that $80 \%$ of male, $16 \%$ of female and $4 \%$ of Children died on Road crashes/collision in Ondo State in the Year 2010.

\subsection{CONCLUSION AND RECOMMENDATION}

The figure 7 below shows the Period of the year 2005 to 2010, according to statistical information the following Factors are identified and documented as main factors responsible for crashes/collisions on Ondo State Roads.

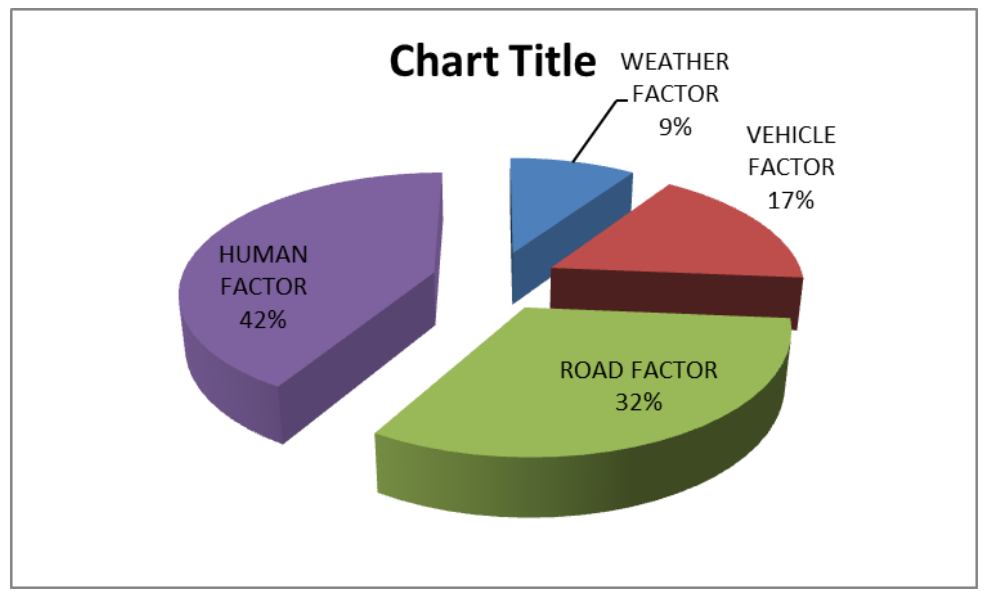

FIG 7a percentage distribution of the factor

The Figure 7a shows the percentage distribution of factors responsible for crashes/collisions on Ondo State from the month of January 2005 to the month of December 2010.The highest percentage (42\%) and is attributed to human error followed by Vehicle Maintenance $32 \%$ and lowest $(17 \%)$ is attributed to Nature (Weather =Rain, clod, Flood, Gale etc.). These factors occur in different degrees, psychologically, Nigerians are always in a hurry, and they want to get to many places without thinking about the scale of their actions. Negligence contribute to Human errors and at the same time laxity contribute to vehicle maintenance problem which is still in line with human error. Some of the crashes/collisions that have occurred on Ondo State's Roads should not have occurred if vehicle operators had recognized the danger in speeding when it is heavily shower or windy. From the year 2005 January to December 2010 about 841 persons were killed while 3871 persons sustained different degree of Degrees of injuries. There is no year pass by without deaths/injuries being reported on Ondo State roads. In 2005 going by the months, despite there no report of deaths in the month of June but in 
August, 6 people killed And 15 persons suffered different degree of injuries. In that year going by the Calendar year only one person suffered injury/death on Ondo State road daily. In the year 2006, February, August and November there was no report of deaths Roads but 46 people suffered different degree of injuries. In the year 2007, there was no month recorded without deaths. Based on Calendar year about 15 people killed while74 persons sustained different degree of injuries on Ondo State roads every month. Going by total casualties about 3 persons suffered different category of injuries/death every day on Ondo State Roads that year. Similarly in the year 2008 going by the calendar year, roughly11 people died

on Ondo State Roads while 83 sustained different degree of injuries on Ondo State Roads every month. Going by the Calendar days in that year about 3 people sustained serious injuries/deaths rate every day on Ondo State Roads. In 2009, going by the calendar year averagely about 12 people killed and about 50 people sustained categories of Injury on Ondo State road every month. Going by daily activities 2 people sustained injuries daily on Ondo state roads.

In the year 2010 throughout the whole year no month went without people being killed in vehicle crashes/collisions except the month of December. Going by the calendar year, about 22 people killed and about 86 persons sustained injuries on Ondo State Roads every month. In that very year about 4 people sustained injury /death daily on Ondo state. Roads.

\subsection{1: RECOMMENDATION}

lly, As noted from the analysis there are rooms for preventive measures if introduced to reduce the rate of crashes/collisions acon on the Ondo State Roads Ondo roads. This includes: Road safety education, Promoting accident prevention education, aining, Enforcement of Seat belt and Child restraints Improving road design and positioning of traffic signs, Broken-down vehicle be moved off the road immediately, Introduce Public road safety education and awareness and Enforcement of Speed Limits laws.

\section{BIBLOGRAPHY}

[1] NPC (The National Population Commission)(2006):

[2] http://www.population.gov.ng/

[3] Pan Arab Journal of Neurosurgery (1998):

[4] http://www.panarabneurosurgery.org.sa/journal/oct1998/implicationOfRoadAccidents.htm

[5] J.R Aworemi (2010):http://interesjournals.org/ER/pdf/2010/May/Aworemi\%20et\%20al.pdf

[6] Joksch (1993):http://www.ncbi.nlm.nib.gov/pubmed/8420529

[7] Online Library of the OECD (July 2010): http://en.wikipedia.org/wiki/OECD

[8] http://en.wikipedia.org/wiki/Highway (14 July 2009)

[9] http://en.wikipedi.org/wiki/Road_safety (4 July 2009)

[10] http://en.wikipedia.org/wiki/roadtrafficsafety (March 2009)

[11] http://en.wikipedia.org/wiki/road_traffic_safety (March 2009)

[12] http://www.medwelljournals.com/fulltext/?dol=jmcomm.2010.68.74

[13] Sleep SOS report. Royal Society for prevention of Accidents, (2004)

[14] (http://seriousaccidents.com/legal.../top-cause-of-car-accidents/).

[15] Pan Arab Journal of Neurosurgery (1998)

[16] http://www.panarabneurosurgery.org.sa/journal/oct1998/implicationOfRoadAccidents.htm 